See discussions, stats, and author profiles for this publication at: https://www.researchgate.net/publication/268483024

\title{
Low Cost Catalysts for Hydrazine Monopropellant Thrusters
}

Conference Paper · August 2009

DOI: 10.2514/6.2009-5232

CITATIONS

READS

2

53

5 authors, including:

Gat Jose Nivaldo Hinckel

21. National Institute for Space Research, Brazil

27 PUBLICATIONS $\mathbf{5 0}$ CITATIONS

SEE PROFILE 


\title{
Low Cost Catalysts for Hydrazine Monopropellant Thrusters
}

\author{
José Nivaldo Hinckel ${ }^{*}$ \\ INPE/DMC, São José dos Campos, SP, 12201-970, Brazil

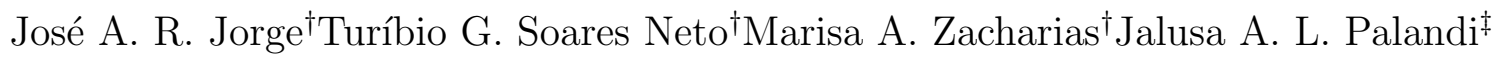 \\ INPE/LCP, Cachoeira Paulista, SP, 12630-000, Brazil
}

\begin{abstract}
Hydrazine monopropellant engines are widely used in space missions; mainly in reaction control systems. The most widely used catalyst is the aluminum oxide supported iridium. It is also very expensive. The cost of the catalyst weights heavily, especially in the high thrust, short life thrusters used for roll control of launch vehicles. In this paper we present the results of testing of low cost catalysts in a 35 newton thruster. The catalysts tested were aluminum oxide supported ruthenium and a homogeneous catalyst, tungsten carbide. The test sequence included pre-heated and cold starts, pulsed and continuous firing modes, a range of feed pressure and life cycle that exceed the requirements of roll control systems. The start and energetic performance of the thruster matched very closely the performance of the iridium catalyst.
\end{abstract}

\section{Nomenclature}

$\begin{array}{llllll}C^{*} & {[\mathrm{~m} / \mathrm{s}]} & \text { Characteristic Velocity } & P_{c} & {[\mathrm{MPa}]} & \text { Chamber Pressure } \\ C_{f} & & \text { Thrust Coefficient } & t_{i g} & {[\mathrm{~ms}]} & \text { Ignition time } \\ F & {[\mathrm{~N}]} & \text { Thrust } & t_{r e s p} & {[\mathrm{~ms}]} & \text { Response time } \\ I_{s p} & {[\mathrm{~m} / \mathrm{s}]} & \text { Specific Impulse } & T_{i n} & {\left[{ }^{\circ} \mathrm{C}\right]} & \text { Initial Temperature } \\ P_{i} & {[\mathrm{MPa}]} & \text { Injection Pressure } & & & \end{array}$

\section{Introduction}

The development of monopropellant thrusters and performace characteristics are well documented in the literature. Schmitz ${ }^{1}$ describes the qualification test sequence for a long life, iridium catalyst, 2 newton

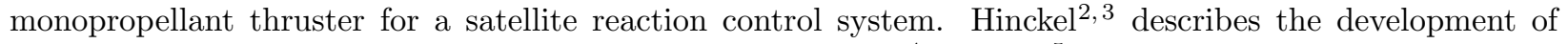
hydrazine monopropellant thrusters carried out at INPE. Rath ${ }^{4}$ and Pitt ${ }^{5}$ describe the development of a 400 $\mathrm{N}$ monopropellant engine.

The life cycle and thrust level requirements of control thrusters, depend strongly on the mission application. The two main applications are in roll control systems of upper stages of launch vehicles and reaction control systems of satellites and space platforms. Thrusters used in roll control systems have a thrust level in the hundreds of newton, accumulated working time of a few hundred seconds and operating life of approximately 600 seconds. The duty-cycle varies from short pulses of hundreds of milliseconds to continuous firings of up to one minute. Thrusters used in reaction control systems of satellites have a thrust of a fraction of one newton to tens of newton, accumulated operating time of a few hours, operating life of 10 to 15 years. The duty-cycle varies from short pulse trains with dozens of pulses to continuous firings with duration up to one hour.

\footnotetext{
*Senior Researcher, and AIAA Senior Member.

†Senior Researcher

$\ddagger$ Graduate student
} 
The amount of catalyst loaded is roughly proportional to the nominal thrust of the engine, varying from less than one gram for a 1 newton thruster to 300 grams for $400 \mathrm{~N}$ thruster. The catalyst cost consideration is of minor importance in long life thrusters for satellite reaction control systems. For short life, high thrust level engines, for roll control systems, the cost of the catalyst is significant.

In this paper we describe the results o fire test with two catalysts whose production costs are substantially lower than the widely used aluminum oxide supported iridum catalyst. The test were carried out in a chamber designed for nominal thrust of 35 newton. The catalysts tested were; an heterogenous aluminum oxide supported ruthenium catalyst and a homogeneous catalyst, tungsten carbide. Applications of the ruthenium in monopropellant control thruster ared described in the literature, $\mathrm{Pitt}^{5}$. Applications of aluminum oxide

supported tungsten carbide and homogeneous tungsten carbide catalysts in monopropellant thrusters are reported by $\mathrm{Chen}^{6}$ and Rodrigues ${ }^{7}$, respectively. Scaling up for thrust levels of 200 newton and 400 newton

is now under way.

\section{The Catalyst}

The catalyst is responsible for starting the decomposition of propellant in the chamber. It acts by decreasing the activation energy for the reaction of decomposition of the propellant, ensuring a smooth start even for a chamber bed temperature well bellow the temperature for thermal decomposition of the propellant. The decomposition of the propellant due to the action of the catalyst is referred to as an heterogenous reaction while the the thermal decomposition is referred to as homogeneous reaction. A substance is said to have a catalytic effect on the decomposition reaction if it decreases the temperature for decomposition of the hydrazine bellow de thermal decomposition threshold. A catalyst that is capable of sustaining the decomposition of hydrazine at temperatures bellow $35^{\circ} \mathrm{C}$ is termed a spontaneous catalyst.

Two types of catalysts were produced and tested; aluminum oxide supported ruthenium, and a homogeneous catalyst, tungsten carbide.

\section{A. The ruthenium catalyst}

The production of the ruthenium catalyst comprises two phases; the aluminum oxide support preparation and the metallic impregnation. The main characteristics of the aluminum oxide support are shown in Table 1. The metallic impregnation is done in six phases. The weight fraction of the metallic component in the catalyst is $33 \%$. Between each phase of the impregnation process the aluminum oxide suport is first dried in a oven at $120^{\circ} \mathrm{C}$ and then in a vacuum chamber at ambient temperature and 1 mbar pressure. After the drying phase the catalyst was reduced in $\mathrm{H}_{2}$ medium at $400{ }^{\circ} \mathrm{C}$ during 4 hours.

\begin{tabular}{|l|l|l|l|l|l|l|}
\hline \multirow{2}{*}{ Textural property } & \multicolumn{2}{|c|}{ Aluminum support } & \multicolumn{2}{c|}{ Catalyst before firing } & \multicolumn{2}{c|}{ Catalyst after firing } \\
\cline { 2 - 7 } & Spheroid & Pelletized & Spheroid & Pelletized & Spheroid & Pelletized \\
\hline Specific area & $165 \mathrm{~m}^{2} / \mathrm{g}$ & $184 \mathrm{~m}^{2} / \mathrm{g}$ & $93 \mathrm{~m}^{2} / \mathrm{g}$ & $103 \mathrm{~m}^{2} / \mathrm{g}$ & $81 \mathrm{~m}^{2} / \mathrm{g}$ & $73 \mathrm{~m}^{2} / \mathrm{g}$ \\
\hline Volume of pores & $0.38 \mathrm{~cm}^{3} / \mathrm{g}$ & $0.38 \mathrm{~cm}^{3} / \mathrm{g}$ & $0.15 \mathrm{~cm}^{3} / \mathrm{g}$ & $0.16 \mathrm{~cm}^{3} / \mathrm{g}$ & $0.15 \mathrm{~cm}^{3} / \mathrm{g}$ & $0.16 \mathrm{~cm}^{3} / \mathrm{g}$ \\
\hline Mean pore diameter & & & $64 \AA$ & $59 \AA$ & $74 \AA$ & $80 \AA$ \\
\hline
\end{tabular}

Table 1. Rutenium catalyst characteristics

The following measuring techniques are used in the characterization process:

Gravimetry: is used to measure the metallic contents of the catalyst.

Nitrogen Fisissorption: is used to measure the specific area.

Nitrogen adsorption: the pore size and distribution measurement was carried out by nitrogen adsorption at its normal condensation temperature.

Transmission electronic microscopy: is used to measure the distribution and size of the metallic particles on the surface of the catalyst pores. 
The evolution of the specific area and the pore size distribution and volume was measured after each phase of the metallic impregnation process.

After the fire test program the catalyst was collected and analyzed for loss of mass, quantity of fines generated, specific area and pore size, volume and distribution.

\section{B. The tungsten carbide catalyst}

The sinthesys of the tungsten carbide is done in two phases. In the first phase a precursor to the carbide is obtained. In the second phase the tungsten carbide is obtained..

\section{Synthesis of the carbide precursor}

The synthesis of the carbide precursor starts from a mixture of powder of tungstic acid and aluminum hydroxide. The mixture is then subjected to a controlled dispersion process with a chemical agent, resulting in a moldable paste which is extruded forming pellet with diameter of $2.5 \mathrm{~mm}$ and length of $2.6 \mathrm{~mm}$. The pellets are dried at $50^{\circ} \mathrm{C}$ and subsequently calcinated at $900^{\circ} \mathrm{C}$ during $1 \mathrm{~h}$.

\section{Synthesis of the tungsten carbide}

\begin{tabular}{|l|l|l|}
\hline Characteristic & Before firing & after firing \\
\hline Specific area & $70 \mathrm{~m}^{2} / \mathrm{g}$ & $22 \mathrm{~m}^{2} / \mathrm{g}$ \\
\hline Volume of pores & $0.09 \mathrm{~cm}^{3} / \mathrm{g}$ & $0.04 \mathrm{~cm}^{3} / \mathrm{g}$ \\
\hline $\begin{array}{l}\text { Mean pore di- } \\
\text { ameter }\end{array}$ & $51 \AA$ & $76 \AA$ \\
\hline $\begin{array}{l}\text { Mechanical re- } \\
\text { sistance }\end{array}$ & $23 \mathrm{~N} / \mathrm{mm}^{2}$ & $12 \mathrm{~N} / \mathrm{mm}^{2}$ \\
\hline
\end{tabular}

The aluminum-tungsten oxide composite is carburized in a quartz reactor by an $80 \%$ methane $20 \%$ hydrogen

Table 2. Tungsten carbide characteristics mixture under a programmed temperature schedule. The carbide is then passivated in a mixture of helium with $1 \%$ dispersed oxygen.

The main characteristics of the tungsten carbide are shown in Table 2. A picture of the tungsten carbide catalyst pellet magnified 35 times, before and after the fire test is shown in Fig. 1

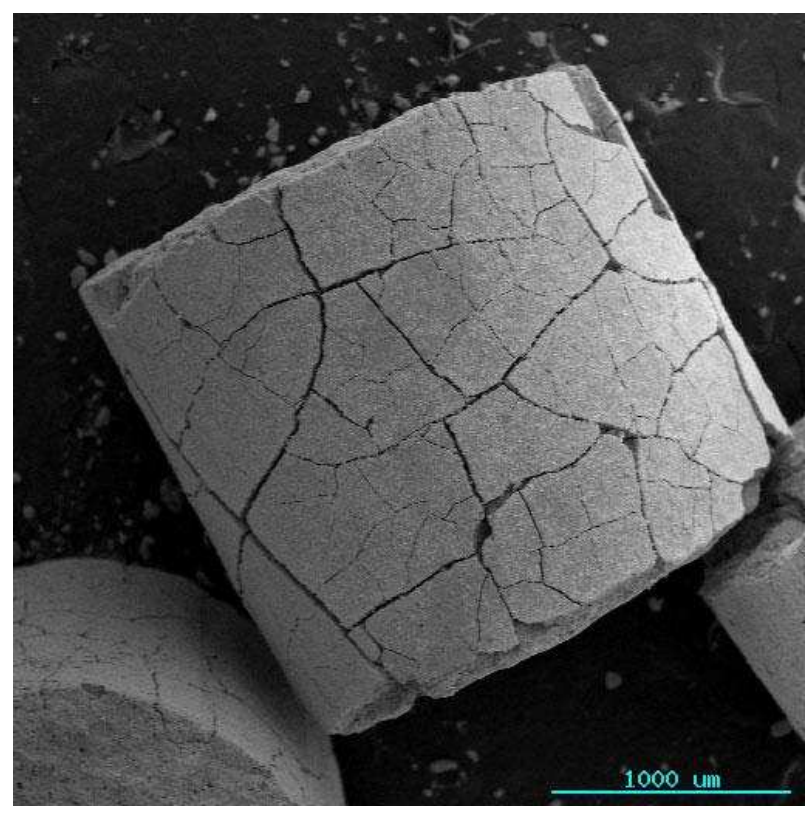

(a) Tungsten Carbide (35X) before fire test

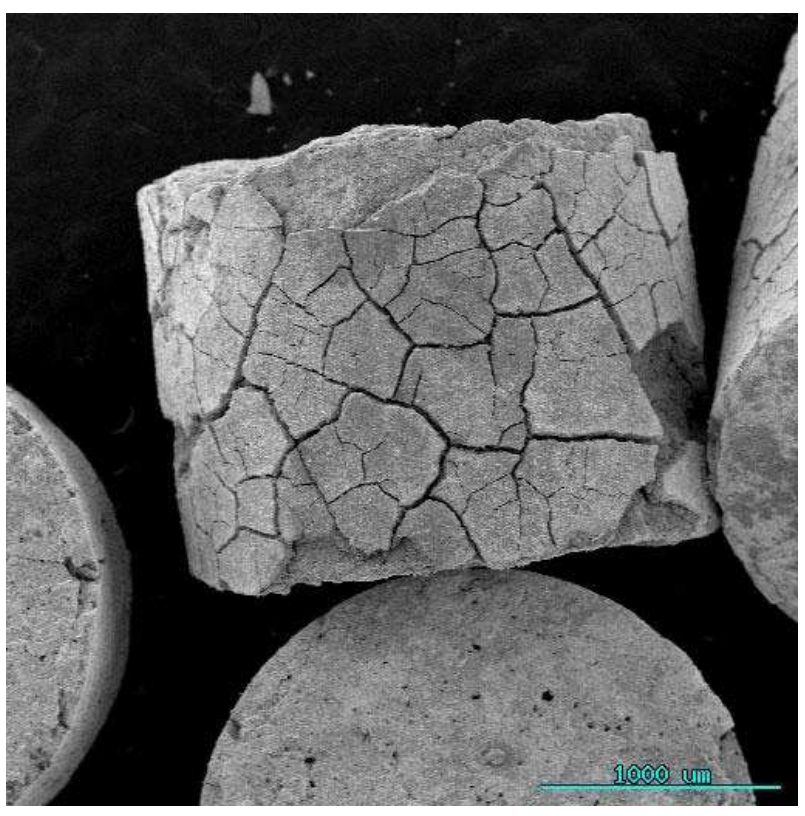

(b) Tungsten Carbide (35X) after fire test

Figure 1. Tungsten carbide catalyst before and after the fire test 


\section{The test engine}

The test engine geometry, shown in Figure 2, is composed of the injector head, the catalyst chamber and the expansion nozzle.

The engine was designed for operation in the feed pressure range of $2.2 \mathrm{MPa}$ to $0.55 \mathrm{MPa}$ with nominal thrust of $35 \mathrm{~N}$ at $2.2 \mathrm{MPa}$ feed pressure. The corresponding catalytic bed load is 2.75 to $0.9 \mathrm{~g} / \mathrm{cm}^{2} \cdot \mathrm{s}$. The design values for the injector pressure drop and catalytic chamber pressure drop for a feed pressure of 2.2 MPa are $0.5 \mathrm{MPa}$ and $0.2 \mathrm{MPa}$ respectively.

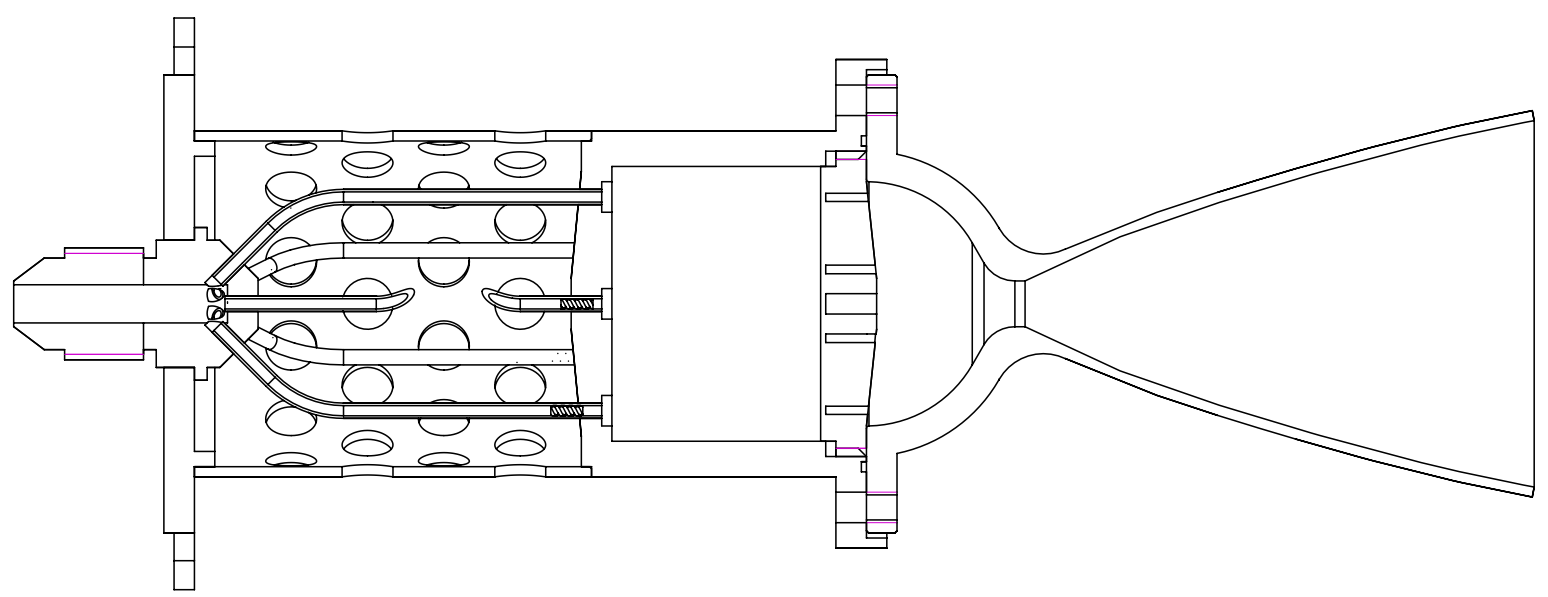

Figure 2. Thruster drawing

\section{A. The injector head}

The injector head comprises seven capillary tubes each one with an helical insert at the exit for atomization and metering of the propellant. The pattern distribution of the injector elements over the face plate is shown in Fig 3. One injector element is placed at the center and six elements are distributed in a ring. The wetted area of each injector element is approximately the same.

The helical insert with two entrances has a length of $2 \mathrm{~mm}$ and is placed $2.5 \mathrm{~mm}$ from the end of the capillary tube. The mass flow of each injector element is calibrated by adjusting the exit diameter of the tube. Each injector discharges into a small cylindrical chamber with a length of $1 \mathrm{~mm}$ and $3 \mathrm{~mm}$ diameter. Inside the chamber, the injected propellant forms a conical trunk sheet. The base of trunk is limited by the bottom screen and the top of the trunk is the exit diameter of the capillary injector. The main design parameters of the thruster are:

\section{B. The catalytic chamber}

The catalytic chamber is cylindrical with a length of $20 \mathrm{~mm}$. Three mesh 60 platinum screens are used inside the chamber; one at the injector face plate, one to separate the fine catalyst layer from the coarse layer and one at the end of the coarse layer. A perforted disk with an outside thread is used to support the retaining screen and to apply a small load onto the catalytic bed for better packing. An insulated heating wire is wrapped around the catalytic chamber. The power dissipation of the heating wire is approximately $15 \mathrm{~W}$. The catalytic chamber filled with the coarse catalytic layer is shown in Figure 3.

For loading the catalyst, the chamber was mounted onto a shaker. A vibration movement of $1.5 \mathrm{~g}$ acceleration and frequency of $250 \mathrm{~Hz}$ was applied.

\section{The Expansion Nozzle}

The nozzle is connected to the catalytic chamber by bolted flanges. Sealing between the chamber and the nozzle is provided by a metallic ring. The throat diameter of the nozzle is $4.5 \mathrm{~mm}$ and the expansion area ratio is 64 . The divergent nozzle with total length of $50 \mathrm{~mm}$ is parabolic with an opening angle of $36^{\circ}$ and and exit angle of $10^{\circ}$. 


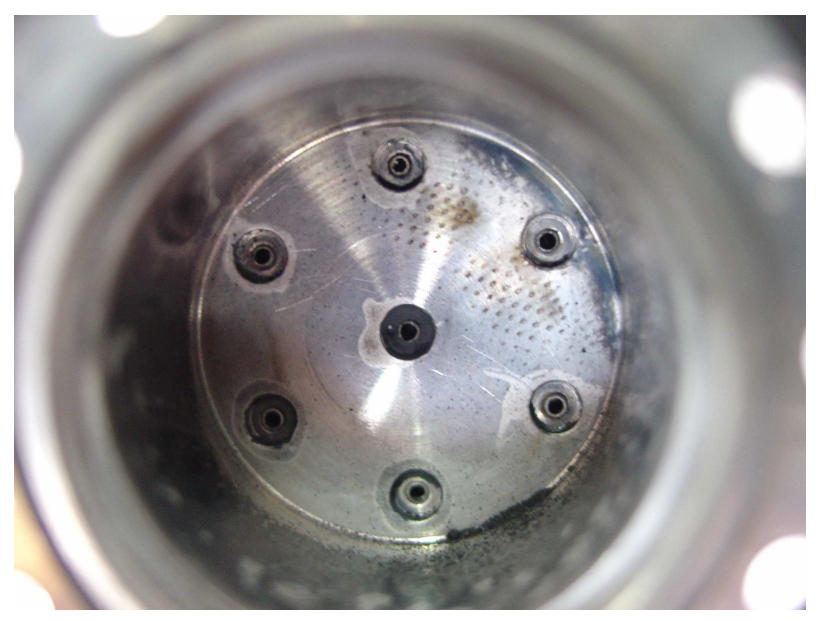

(a) Injector face plate

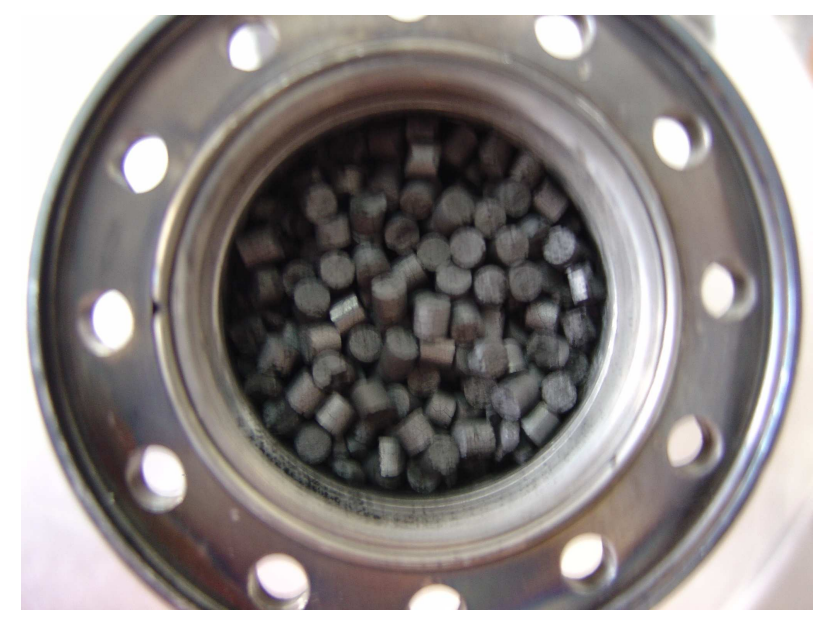

(b) Second layer, tungsten carbide

Figure 3. Catalyst chamber and catalyst layers

\section{The Test Facility}

The test facility is located in Cachoeira Paulista and is operated by the local Division of Combustion and Propulsion of INPE. The test facility is equipped with an $10 \mathrm{~m}^{3}$ test chamber, a high pumping speed vacuum system, propellant conditioning feed system, a control room for the vacuum system, propellant conditioning and thruster operation and data acquisition and processing system. The vacuum pumping system comprises two series mounted vapor ejectors, one condenser unit, two liquid ring mechanical pumps, one gas-liquid separator and and mechanical pumps for non-condensible products.

The facility instrumentation consists of a thrust balance, propellant feed line pressure and temperature measurement, propellant mass flow rate and thermocouples and pressure transducers for measurement of the thruster wall temperature, propellant feed pressure and temperature and nozzle entrance chamber pressure.

Two computer controlled units are used for the operation of the facility; one unit commands the vacuum system, the propellant feed system and the thruster propellant valve, the other unit does the data acquisition and data processing functions.

The thruster is mounted in the vertical position with the exhaust jet directed downward.

\section{The test program}

Two catalyst loads were tested. In the first load both layers of the catalytic chamber were filled with the alumina supported ruthenim catalyst. In the second load the first layer was load with alumna supported iridium and the second layer was load with tungsten carbide pellets. Before the firing test the vacuum chamber was pumped down to a pressure bellow $1 \mathrm{mbar}$ and the catalytic chamber was heated to a temperature of $120^{\circ} \mathrm{C}$ for a period of at least 2 hours. An initial firing test of 5 seconds was carried out before the main test sequence. The purpose of this test was to verify the working condition of the thruster and to reduce any oxidation of the catalyst that might have occurred during the test preparation. The test program was designed to verify the operation of the thruster over the working feed pressure range and duty-cycle. Three levels of feed pressure

\begin{tabular}{|r|r|r|r|r|}
\hline $\mathrm{P}_{i}$ & $\mathrm{t}$ & $t_{\text {on }} / t_{\text {off }}$ & $\mathrm{NP}$ & $\mathrm{T}_{\text {in }}$ \\
\hline $\mathrm{MPa}$ & $\mathrm{s}$ & $\mathrm{ms} / \mathrm{ms}$ & & ${ }^{\circ} \mathrm{C}$ \\
\hline 1.2 & 5 & - & 5 & 120 \\
2.2 & 100 & $500 / 500$ & 100 & 120 \\
\hline 2.2 & 100 & $200 / 500$ & 100 & 120 \\
\hline 2.2 & 30 & - & 1 & 120 \\
\hline 1.2 & 100 & $500 / 500$ & 100 & 120 \\
\hline 1.2 & 100 & $200 / 800$ & 100 & 120 \\
\hline 1.2 & 30 & - & 1 & 120 \\
\hline 5.5 & 100 & $500 / 500$ & 100 & 120 \\
\hline 5.5 & 100 & $200 / 800$ & 100 & 120 \\
\hline 5.5 & 30 & - & 1 & 120 \\
\hline 5.5 & 30 & $200 / 800$ & 30 & 25 \\
\hline
\end{tabular}

Table 3. Test program 
were tested: $2.2,1.2$ and $0.55 \mathrm{MPa}$. For each pres-

sure level the thruster was fired in continuous mode, and pulsed mode. The complete sequence of test conditions for each catalyst load is presented in Table 3. A cold start test was performed as the last test in the sequence.

\section{Summary of test results}

The steady state performance of the thruster is shown in Table 4 for three levels of feed pressure. $\mathrm{P}_{i}$ is the feed pressures at valve entrance, $\mathrm{P}_{c}$ is the chamber pressure at the beginning of the convergent section of the nozzle, $\mathrm{T}$ is the thrust, $\mathrm{I}_{s p}$ is the specific impulse, $\mathrm{C}^{*}$ is the characteristic velocity and $\mathrm{C}_{f}$ is the thrust coefficient. The thrust level is slightly higher than the design value ( $35 \mathrm{~N}$ for a feed pressure of $2.2 \mathrm{MPa})$. The reason for this is that the injector pressure drop and the catalytic bed pressure drop were lower than the reference design values.

The "ignition" characteristics of the thruster are shown in Table 5. The table shows the characteristic times for the first pulse and last pulse in a pulse train with 100 pulses. The pulse frequency was $1 \mathrm{~Hz}$ and the duty-cycle $50 \% . \mathrm{P}_{i}$ is the feed pressures at valve entrance. $T_{i n}$ is the temperature of the catalyst bed at the beginning of the pulse train. The response time, $\mathrm{t}_{\text {resp }}$, is the time interval between the opening of the valve and the instant when the chamber pressures attains $10 \%$ of the steady state value. The ignition time, $\mathrm{t}_{i g}$ is the time interval between the valve opening

\begin{tabular}{|r|r|r|r|r|r|}
\hline $\mathrm{P}_{i}$ & $\mathrm{P}_{c}$ & $\mathrm{~F}$ & $\mathrm{C}^{*}$ & $\mathrm{I}_{s p}$ & $\mathrm{C}_{f}$ \\
\hline $\mathrm{MPa}$ & $\mathrm{MPa}$ & $\mathrm{N}$ & $\mathrm{m} / \mathrm{s}$ & $\mathrm{m} / \mathrm{s}$ & \\
\hline 2.17 & 1.46 & 40.9 & 1246 & 2184 & 1,75 \\
\hline 1.20 & 0.88 & 24.3 & 1189 & 2047 & 1.72 \\
\hline 0.57 & 0.44 & 11.8 & 1116 & 1856 & 1.66 \\
\hline
\end{tabular}

Table 4. Steady state performance and the instant when the chamber pressure attains the value of $75 \%$ of the steady state value. The last line of the table shows the results for a cold start.

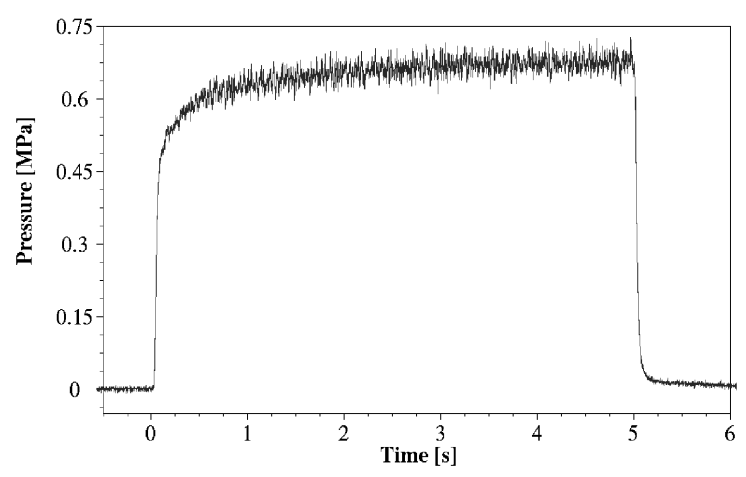

(a) $5 \mathrm{~s}$ Continuous mode

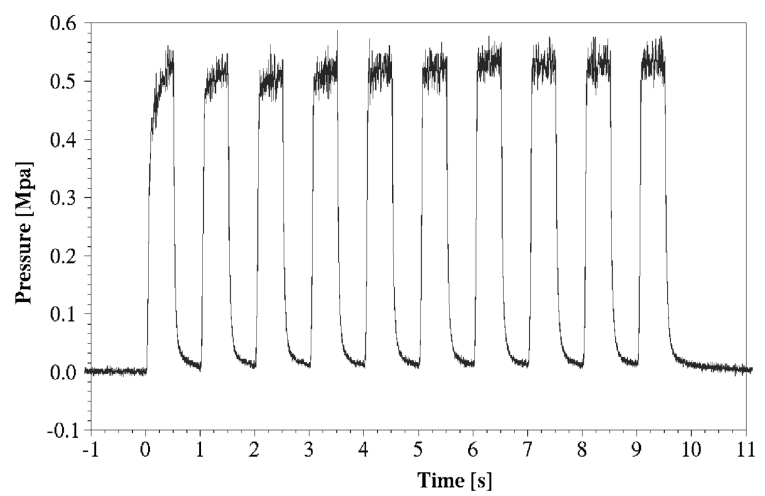

(b) 10 pulse train

Figure 4. Pressure trace of continuous and pulsed modes

\section{Acknowledgment}

The authors would like to thank FAPESP (PN 05/03605-4) for the support for the development of the catalyst. We also thank the LCP researcher David dos Santos Cunha for de production iridium aluminum catalyst and the BTSA staff for carrying out the fire test program, and Gilberto Marques da Cruz and Gerald Djéga-Mariadassou for the valuable comments and discussions on the catalyst properties and thruster test results.

\section{Conclusion}


Low cost catalysts (aluminum oxide suported ruthenium, and tungsten carbide) were produced and tested in a 35 newton catalytic engine. The energetic performance and characteristic response time are very close to those of the iridium catalyst. These catalysts may reduce significantly the production cost of high thrust, short operational time of thrusters for roll control of launch vehicles.

The test programm covered the operational envelope of thrusters used for roll control of launch vehicles, regarding propellant feed pressure, duty-cycle and propellant throughput.

No significant degradation of the of the catalyst performance was observed during the tests. The loss of catalyst mass and generation of fines measured after the tests was negligible.for the tungsten carbide calyst. For the ruthenium catalyst a $20 \%$ loss of mass was observed. The mechanism responsible for this loss is being investigated.

Scaling up to thrusters with thrust level of $400 \mathrm{~N}$ is under way. Operational margins on propellant chamber load will be tested in order to determine possible reduction of catalytic chamber diameter and catalyst load.

\section{References}

${ }^{1}$ Schimtz, H. D., Tiedtke, P., and Steenborg, M., "Design, Development and Qualification of the OTS/MAROTS Monopropellant Hydrazine Thrusters," No. AIAA-77-966, AIAA/SAE 13th Joint Propulsion Conference, Orlando, FL, July 11-13 1977.

${ }^{2}$ Hinckel, J. N., Trava-Airoldi, V., Corat, E., and Bressan, C., "Propulsion Subsystem Component Development for he MECB RSS Satellite," No. AIAA-91-1836, AIAA/SAEASME/ASEE 27th Joint Propulsion Conference, Sacramento, CA, June 24-26 1991.

${ }^{3}$ Hinckel, J. N., "Development of a 115 Newton Thrust Hydrazine Catalytic Thruster," No. AIAA-93-1964, AIAA/SAE/ASME/ASEE 29th Joint Propulsion Conference, Monterey, CA, June 28-30 1993.

${ }^{4}$ Rath, M., Schimtz, H. D., and Steenborg, M., "Development of a $400 \mathrm{~N}$ Hydrazine Thruster for ESA's Atmospheric Reentry Demonstrator," No. AIAA-96-2866, 32nd AIAA/ASME/SAE/ASEE Joint Propulsion Conference, Lake Buena Vista, FL, July 1-3 1996.

${ }^{5}$ Pitt, R. and Rogall, H., "Design, Development and Evolution of the Ariane 5 Attitude Control System (SCA)," No. AIAA-95-2808, 31st AIAA/ASME/SAE/ASEE Joint Propulsion Conference and Exhibit, San Diego, CA, July 10-12 1995.

${ }^{6}$ Chen, X., Zhang, T., Zheng, M., Xia, L., Li, T., Wu, W., Wang, X., and Li, C., "Catalytic Decomposition of Hydrazine over $\alpha-\mathrm{Mo}_{2} \mathrm{C} / \gamma-\mathrm{Al}_{2} \mathrm{O}_{3}$ Catalysts," Industrial \&S Engineering Chemistry Research, Vol. 43, No. 19, August 2004, pp. 6040-6047.

${ }^{7}$ Rodrigues, J. A. J., Cruz, G. M., Bugli, G., Boudart, M., and Djéga-Mariadassou, G., "Nitride and carbide of molybdenum and tungsten as substitutes of iridium for catalysts used for space communications," Catalysis Letters, Vol. $45,1997$. 